\title{
Oxidative stress and expression of inflammatory factors in lung tissue of acute mountain sickness rats
}

\author{
XIAOYAN PU ${ }^{1,2^{*}}$, FUXIN LI $^{2 *}, \mathrm{XUE} \mathrm{LIN}^{2}, \mathrm{RONG}^{2} \mathrm{WANG}^{2}$ and $\mathrm{ZHI} \mathrm{CHEN}{ }^{1}$ \\ ${ }^{1}$ Qinghai Normal University and ${ }^{2}$ College of Medicine, Qinghai University, Xining, Qinghai 810001, P.R. China
}

Received October 16, 2019; Accepted January 27, 2021

DOI: $10.3892 / \mathrm{mmr} .2021 .12565$

\begin{abstract}
The aim of the present study was to investigate the changes in lung histomorphology and oxidative stress, as well as the expression of interleukin (IL)-17C and other inflammatory factors during acute mountain sickness (AMS) in male Sprague-Dawley rats and to explore the underlying mechanism. Rats were randomly divided into a control group $(0 \mathrm{~h})$ and three hypoxia stress groups, exposed to low-pressure oxygen storage at a simulated altitude of $6,000 \mathrm{~m}$ for 24,48 and $72 \mathrm{~h}$, respectively. Morphological changes in lung tissue were observed by hematoxylin and eosin staining under light microscopy and transmission electron microscopy. The expression of inflammatory factors IL-17C, nuclear factor- $\kappa \mathrm{B}$ $(\mathrm{NF}-\kappa \mathrm{B}), \mathrm{IL}-1 \beta$, IL-6 and tumor necrosis factor- $\alpha$ (TNF- $\alpha)$ in lung tissue was assessed by RNA sequencing and verified by reverse transcription-quantitative PCR (RT-qPCR) and western blotting (WB). Superoxide dismutase (SOD) and glutathione peroxidase (GSH-Px) enzyme activity and malondialdehyde (MDA) expression were also measured. Experimental groups were compared to the control group following 24,48 and $72 \mathrm{~h}$ of hypoxic stress. Lung tissue suffered from different degrees of injury, and the damage was the most severe after $48 \mathrm{~h}$ of hypoxic stress. RNA sequencing data from the lung tissue of rats from each group suggested that the expression of IL-17C, $\mathrm{NF}-\kappa \mathrm{B}, \mathrm{IL}-1 \beta$, IL- 6 , and TNF- $\alpha$ increased significantly after hypoxic stress. RT-qPCR and WB demonstrated that the expression of IL-17C and NF- $\kappa \mathrm{B}$ increased significantly after hypoxia lasting 48 and $72 \mathrm{~h}$. IL-1 $\beta$ expression increased significantly after hypoxia stress lasting 24 and $48 \mathrm{~h}$, and the expressions of TNF- $\alpha$ and IL- 6 increased significantly after
\end{abstract}

Correspondence to: Professor Zhi Chen, Qinghai Normal University, 38 Wusi West Road, Xining, Qinghai 810001, P.R. China E-mail: czi58@163.com

Professor Rong Wang, College of Medicine, Qinghai University, 16 Kunlun Road, Xining, Qinghai 810001, P.R. China

E-mail:878794913@qq.com

*Contributed equally

Key words: hypoxia, acute mountain sickness, oxidative stress, inflammatory factors hypoxia stress lasting 24,48 and $72 \mathrm{~h}(\mathrm{P}<0.01)$. The enzyme activity of SOD and GSH-Px decreased significantly after lasting 24,48 and $72 \mathrm{~h}$ of hypoxia $(\mathrm{P}<0.01)$, and MDA increased significantly after hypoxic stress lasting 48 and $72 \mathrm{~h}(\mathrm{P}<0.01)$. In conclusion, under hypoxic stress, rats quickly initiate oxidative stress and immune responses. However, with prolonged hypoxic stress time, excessive oxidative stress can further stimulate the immune system in vivo, and release a large quantity of inflammatory factors accumulating in the body. This, in turn, may lead to the occurrence of inflammatory storms and further damage the lung tissue resulting in AMS.

\section{Introduction}

Acute mountain sickness (AMS) is a potentially lethal condition caused by acute hypoxia after ascending to altitudes higher than $2,500 \mathrm{~m}$ in a short time. It is common in high-altitude travelers, and may lead to life-threatening high-altitude conditions such as high-altitude cerebral edema (HACE) or high-altitude pulmonary edema (HAPE) $(1,2)$.

Previous studies suggested that hypoxia stress can induce an oxidative stress reaction, which leads to increases in endogenous reactive oxygen species (ROS), and oxidative stress damage, resulting in body damage (3-5). ROS are very active and unstable, and indirectly reflect the level of oxidative stress, as well as the degree of injury through the enzyme activity of superoxide dismutase (SOD), glutathione peroxidase (GSH-Px) and the expression of malondialdehyde (MDA) $(6,7)$.

Previous studies demonstrated that oxidative stress can induce the production of inflammatory factors (8). The presence of inflammatory cells, immunoglobulins and complement components in the broncho-alveolar lavage fluid of patients with HAPE suggests that inflammatory immune responses can lead to increased permeability of the pulmonary blood barrier and are involved in the occurrence of HAPE (9). In addition, key factors such as nuclear factor- $\kappa \mathrm{B}(\mathrm{NF}-\kappa \mathrm{B})$, interleukin (IL)-1 $\beta$, IL-6, and tumor necrosis factor- $\alpha$ (TNF- $\alpha$ ) serve an important role in the development of exacerbated immune responses, among which IL-1 $\beta$ is an important pro-inflammatory factor (10-13). Activation of the above factors can stimulate the proliferation of vascular smooth muscle cells, which can lead to pulmonary hypertension (14-16). During oxidative stress, vascular endothelial cells can release adhesion factors and monocytes, causing lymphocytes to aggregate into endothelial cells through these two inflammatory factors (17). TNF- $\alpha$ can 
activate neutrophils, release a large number of oxygen-free radicals and proteases, resulting in tissue damage (18). NF- $\mathrm{BB}$ is a transcription regulator. Activation of $N F-\kappa B$ promotes the transcription of cytokines and the activation of inflammatory transmitter gene transcription $(19,20)$. IL-17C is a member of the IL-17 family. Previous studies demonstrated that activated $\mathrm{T}$ cells do not synthesize IL-17C (21), and that epithelial cells from various tissues and organs are the main source of IL-17C (22). IL-17C can promote the secretion of IL-1 $\beta$, IL-6, and $\mathrm{TNF}-\alpha$, activate the $\mathrm{NF}-\kappa \mathrm{B}$ pathway (23), and induce inflammation and immune regulation (24-26). As research has progressed, microorganisms have been shown to promote the expression of IL-17C in epithelial cells in inflammatory environments (27), yet the role of IL-17C and AMS has not been established.

In the present study, it was hypothesized that oxidative stress and inflammatory reactions induced by hypoxia could serve an important role in the onset and development of AMS. To verify this hypothesis and further explore the underlying regulatory mechanism, an AMS rat model was used to study the role and the mechanism of oxidative stress response and inflammatory factors, such as IL-17C, in the occurrence and development of AMS.

\section{Materials and methods}

Establishment of the animal model of AMS. A total of 48 male Sprague-Dawley rats weighing 180-220 g and aged 12 weeks were purchased from the Laboratory Animal Center of The Medical Department of Xi'an Jiaotong University [SCXK (Shaanxi) 2018-001], and kept in a specific pathogen-free at $20^{\circ} \mathrm{C}$ environment. Rats were provided with water and food ad libitum under a 12-h light/dark cycle. Rats were randomly divided into a control group (980 hPa) and simulated acute hypoxic stress groups $(475 \mathrm{hPa})$ for 24,48 and $72 \mathrm{~h}(\mathrm{n}=12$ in each group). The animals in the simulated hypoxia group were placed in a hypobaric oxygen chamber at a simulated altitude of $6,000 \mathrm{~m}$ for the aforementioned periods of time. The altitude in the chamber increased at a uniform speed of $10 \mathrm{~m} / \mathrm{sec}$. The rats were given free access to standard rodent food and water. Then, $30 \mathrm{mg} / \mathrm{kg}$ pentobarbital sodium was injected intraperitoneally to anesthetize the rats. When the breathing of the rat became slow and smooth and muscles were loose, the tissue of both lungs was removed if no traction reflex was observed, and the rat was then decapitated (28). The morphological changes in the right upper lobe lung tissue were detected using hematoxylin and eosin (H\&E) staining under light microscopy and transmission electron microscopy. The remaining lung tissues were immediately stored in three cryopreservation tubes and then subjected to transcriptome sequencing and oxidative stress response evaluation (measurement of SOD levels). The levels of MDA, GSH-Px and inflammatory factors (IL-1 $\beta$, IL-6, IL-17C, NF- $\kappa \mathrm{B}$, and TNF- $\alpha$ ) were also assessed. The measures for handling animals involved in the sampling process were implemented in accordance with the National Regulations on the Administration of Laboratory Animals (GB14923-2010; https://www.cmu.edu.cn/sydwb/info/1835/1388.htm). The animal experiment scheme was assessed and approved by the Ethics Committee of School of Medicine of Qinghai University.
Histomorphological examination of lung tissue. Tissue was harvested from the right upper lobe of the lung, then fixed in $4 \%$ paraformaldehyde for 4 weeks at $4^{\circ} \mathrm{C}$, embedded in paraffin, and sectioned to $5-\mu \mathrm{m}$ thickness. Lung sections were concurrently stained with H\&E ( 95 min) for histopathological examination. Images were captured using a light microscope (magnification, $\mathrm{x} 400$ ).

After dissection, the remaining fresh lung tissues were immersion-fixed in $2.5 \%$ glutaraldehyde for $24 \mathrm{~h}$ at $4^{\circ} \mathrm{C}$. The samples were post-fixed in $1 \%$ osmium tetroxide for $1.5 \mathrm{~h}$ at $4^{\circ} \mathrm{C}$, dehydrated through a series of graded ethanol solutions and 1:1 EPON-812 epoxy resin, and then embedded in EPON-812 epoxy resin. $5 \mathrm{~nm}$ semi-thin sections were stained with toluidine blue for $10 \mathrm{~min}$, blocks trimmed, and ultrathin sections stained with lead citrate and uranyl acetate at room temperature. Specimens were examined using a transmission electron microscope (magnification, x10,000 or 20,000).

RNA sequencing and differential gene screening. Briefly, the total RNA of lung tissue was prepared with an RNA TRIzol ${ }^{\circledR}$ reagent (Thermo Fisher Scientific, Inc.) in accordance with the manufacturer's instructions and agarose gel electrophoresis of extracted RNA performed to ensure sample RNA integrity and inexistence of DNA contamination. Finally, the differentially expressed genes were analyzed by functional annotation and enrichment analysis using clusterProfiler software (http://www.bioconductor.org/packages/release/ bioc/html/clusterProfiler.html) for Gene Ontology functional enrichment analysis of the differential gene sets and Kyoto Encyclopedia of Genes and Genomes (KEGG) (29) pathway enrichment analysis and then the differentially related genes associated with AMS in the IL-17 signaling pathway screened.

Reverse transcription-quantitative PCR (RT-qPCR). A total of $0.1 \mathrm{~g}$ lung tissue was ground in liquid nitrogen and then $1 \mathrm{ml}$ TRIzol $^{\circledR}$ (Thermo Fisher Scientific, Inc.) added to extract the total RNA. The cDNA was obtained using a PrimeScript RT reagent kit with gDNA Eraser (Takara Bio, Inc.). RT-qPCR was performed using a TB Green Premix Ex Taq II (Takara Bio, Inc.) with a PIKORed 96 RT-PCR detection system (Thermo Fisher Scientific, Inc.). All operations were performed in accordance with the manufacturer's protocols. Relative gene expression levels of IL-1, IL-6, IL-17C, NF- $\kappa$ B, and TNF- $\alpha$ were determined using the comparative $2^{-\Delta \Delta \mathrm{Cq}}$ method using $\beta$-actin as endogenous control (30). The thermocycling conditions were: denaturation temperature $94^{\circ} \mathrm{C}$ for $30 \mathrm{sec}$, annealing temperature $56^{\circ} \mathrm{C}$ for $35 \mathrm{sec}$ and extension temperature $72^{\circ} \mathrm{C}$ for $30 \mathrm{sec}$ ( 36 cycles). The primer sequences in this study are shown in Table I. Each experiment was repeated more than three times per tissue to ensure consistency of the experimental results.

Western blot analysis. The protein expressions of IL-1, IL-6, IL-17C, NF- $\kappa \mathrm{B}$, and TNF- $\alpha$ in lung tissues were detected by WB. The lung tissue was homogenized in RIPA containing protease and phosphatase inhibitors (Beyotime Institute of Biotechnology) and lysed on ice for $10 \mathrm{~min}$. The lysate was centrifuged at $12,000 \times \mathrm{g}$ at $4^{\circ} \mathrm{C}$ for $10 \mathrm{~min}$ to collect the supernatant. The total protein concentration was detected using the BCA protein quantification kit (Beyotime Institute of Biotechnology). Subsequently, protein sample was separated 
Table I. Primer sequences for IL-17C, NF- $\kappa$ B, IL-1 $\beta$, IL-6 and TNF- $\alpha$.

\begin{tabular}{lll}
\hline Analyte & \multicolumn{1}{c}{ Forward primer sequence, 5'-3' $^{\prime}$} & \multicolumn{1}{c}{ Reverse primer sequence, 5'-3' $^{\prime}$} \\
\hline IL-1 $\beta$ & AAACAGATGAAGTGCTCCTTCCAGG & TGGAGAACACCACTTGTTGCTCCA \\
IL-17C & GCCTATTTGCCCACCTACAA & AAATTCAGACGGCAAACGAC \\
IL-6 & TGTGTGAAAGCAGCAAAG & AGTCTCCTCATTGAATCCA \\
TNF- $\alpha$ & CGATGAACCACGCCAGTCGCC & GGATGAACACGCCAGTCGCC \\
NF- $\kappa$ B & CGACGTATTGCTGTGCCTTC & TTGAGATCTGCCCAGGTGGTA \\
$\beta$-actin & GAGACCTTCAACACCCAGCC & GCGGGGCATCGGAACCGCTCA
\end{tabular}

IL, interleukin; TNF- $\alpha$, tumor necrosis factor- $\alpha$; NF- $\kappa \mathrm{B}$, nuclear factor- $\kappa \mathrm{B}$.

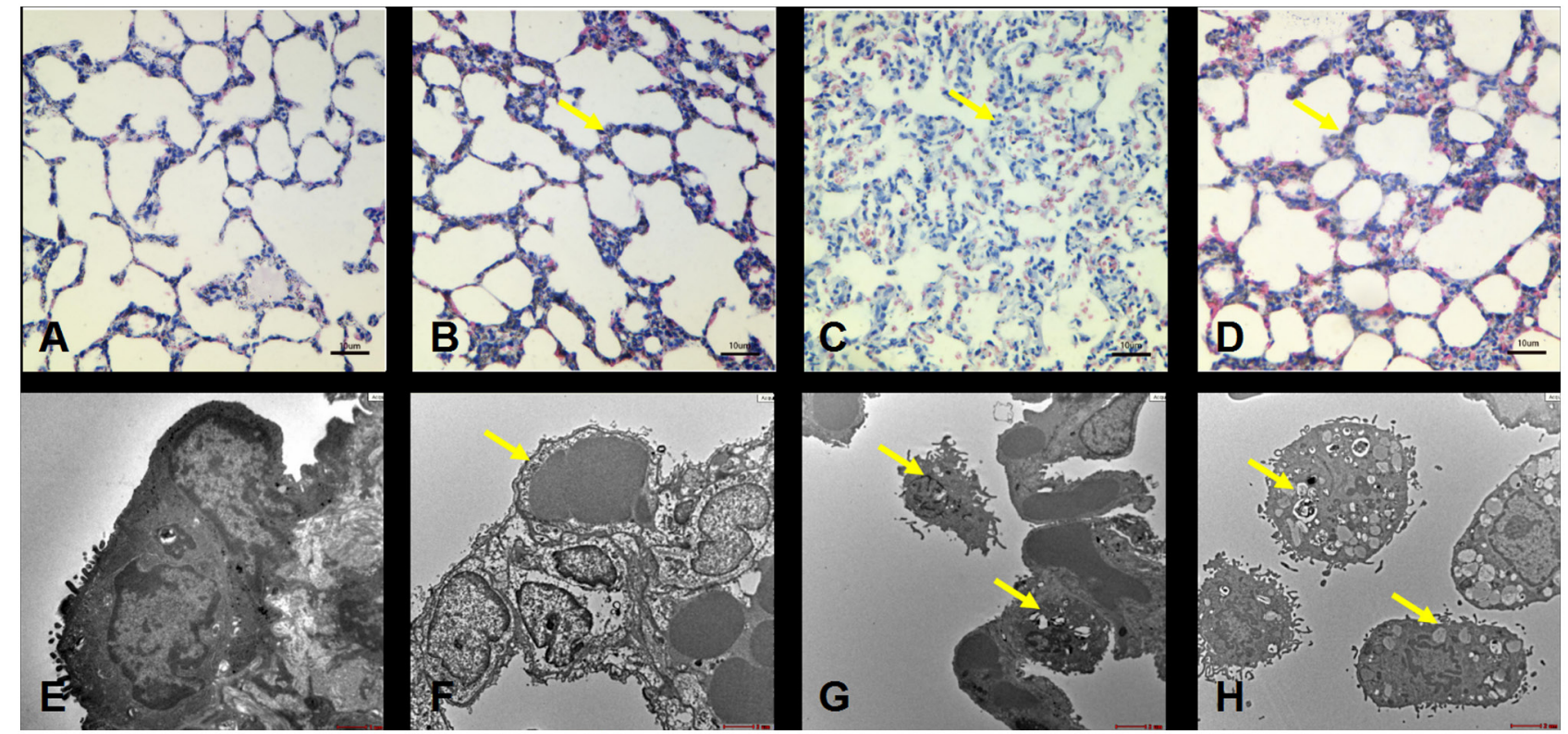

Figure 1. Histomorphological changes in the lungs of Sprague-Dawley rats of different groups. Light microscopy images for the (A) $0 \mathrm{~h}$ group, (B) $24 \mathrm{~h}$ group, (C) $48 \mathrm{~h}$ group and (D) $72 \mathrm{~h}$ group. Scale bar, $10 \mu \mathrm{m}$. Electron microscope for the (E) $0 \mathrm{~h}$ group, scale bar, $1 \mu \mathrm{m},(\mathrm{F}) 24 \mathrm{~h}$ group, scale bar, $500 \mathrm{~nm}$, (G) $48 \mathrm{~h}$ group, scale bar, $1 \mu \mathrm{m}$ ) and $(\mathrm{H}) 72 \mathrm{~h}$ group, scale bar, $500 \mathrm{~nm}$. Pathological changes are indicated by arrows.

on $7 \%$ SDS-PAGE gel with $40 \mu \mathrm{g}$ protein loaded per lane and transferred onto PVDF membranes (Sigma-Aldrich; Merck $\mathrm{KGaA}$ ). PVDF membrane was placed in $5 \%$ skimmed milk diluted with TBST ( $0.1 \%$ Tween) Buffer, incubation box and agitated for $2 \mathrm{~h}$. The PVDF membrane was washed three times with TBST for $5 \mathrm{~min}$ each. The above operations were all performed at room temperature. The primary antibodies anti- $\beta$-actin (1:100,000; cat. no. AC026; Abclonal), anti-IL-1 (1:1,000; cat. no. ab234437; Abcam), anti-IL-6 (1:1,000; cat.no. ab9324; Abcam), anti-IL-17C (1:1,000; cat. no. bs26112; BIOSS), anti-NF-кB, (1:1,000; cat. no. ab32536; Abcam), and anti-TNF- $\alpha$ (1:1,000; cat. no. ab55275; Abcam) were used to detect the relative protein expression in samples and the secondary antibody was Goat Anti-Rabbit IgG H\&L (1:5,000; cat. no. ab6721; Abcam). Images were acquired using Tanon GIS chassis control software v2.0 (Shanghai, China).

Detection of relevant indicators of oxidative stress. The levels of GSH-Px, SOD and MDA in lung tissue were determined using ELISA kits purchased from Shanghai Enzyme Union
Biotechnology Co. Ltd. (cat. nos. m1059387-C, ml097316-C and ml077384-C). Standard curve pore and detection pore were established. Optical density was measured at $450 \mathrm{~nm}$ wavelength using a microplate reader. GSH-Px, SOD and MDA levels were calculated using a standard curve.

Statistical analysis. All data were analyzed using SPSS 22.0 (IBM Corp.) statistical analysis software, and shown as mean \pm standard deviation (SD). One-way analysis of variance (ANOVA) was used with the Tukey HSD post hoc test. Two-tailed Student's t-test were applied to analyze the significant differences between the groups. $\mathrm{P}<0.05$ was considered to indicate a statistically significant difference.

\section{Results}

Morphological changes in rat lung tissue at different time points following hypoxic stress. Lung tissue of the $24 \mathrm{~h}$ group (Fig. 1B) showed thickening of the alveolar septum and inflammatory cell infiltration not visible in the control group (Fig. 1A). 


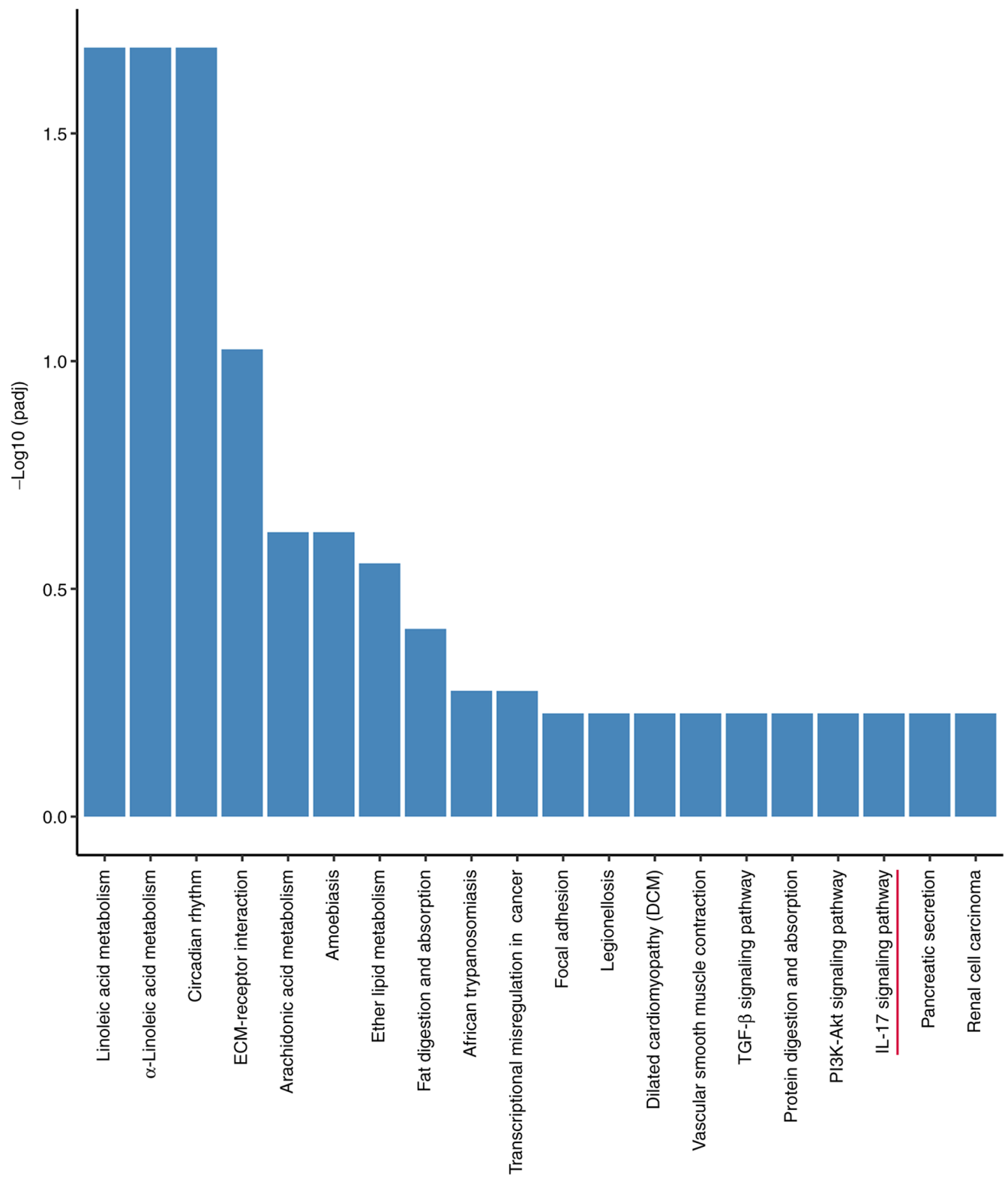

Description

Figure 2. The Kyoto Encyclopedia of Genes and Genomes function classification of differentially expressed genes in the $48 \mathrm{~h}$ group, vs. the $0 \mathrm{~h}$ group. IL-17 signaling pathway is underlined in red.
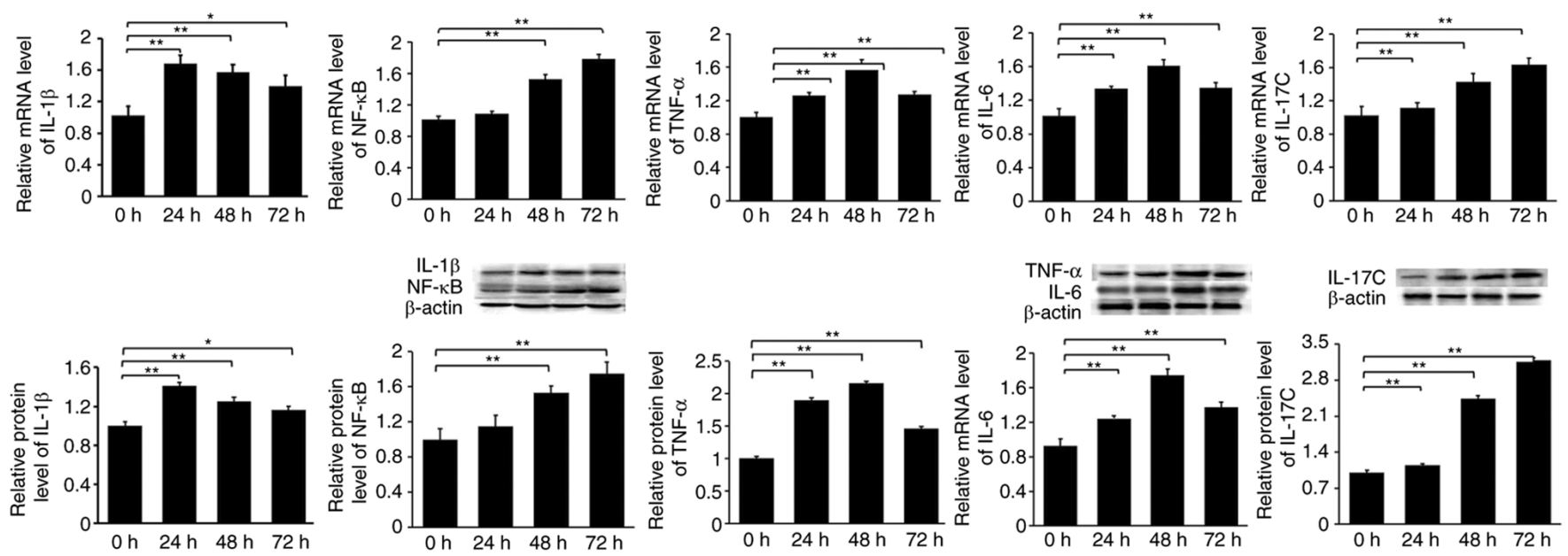

Figure 3. Expression of IL-17C, NF-kB, IL-1 $\beta$, IL-6, and TNF- $\alpha$ in lung tissues of Sprague Dawley rats in different groups; "P $<0.01$ and ${ }^{* * *} \mathrm{P}<0.01$, vs. the 0 h group. 
Table II. Experimental results of oxidative stress in rats of each group.

\begin{tabular}{ccccc}
\hline Group & $\mathrm{n}$ & GSH-Px $(\mathrm{mg} / \mathrm{l})$ & SOD $(\mathrm{Um} / \mathrm{l})$ & $\mathrm{MDA}(\mathrm{nmol} / \mathrm{ml})$ \\
\hline $0 \mathrm{~h}$ & 6 & $4.18 \pm 0.16$ & $2.62 \pm 0.11$ & $0.91 \pm 0.04$ \\
$24 \mathrm{~h}$ & 6 & $3.63 \pm 0.12^{\mathrm{a}}$ & $2.31 \pm 0.15^{\mathrm{a}}$ & $0.91 \pm 0.02$ \\
$48 \mathrm{~h}$ & 6 & $3.47 \pm 0.25^{\mathrm{a}}$ & $2.25 \pm 0.18^{\mathrm{a}}$ & $0.95 \pm 0.04^{\mathrm{a}}$ \\
$72 \mathrm{~h}$ & 6 & $3.93 \pm 0.36^{\mathrm{a}}$ & $2.36 \pm 0.16^{\mathrm{a}}$ & $0.95 \pm 0.04^{\mathrm{a}}$ \\
\hline
\end{tabular}

${ }^{\mathrm{a}} \mathrm{P}<0.01 \mathrm{GSH}-\mathrm{Px}$, glutathione peroxidase; SOD, superoxide dismutase; MDA, malondialdehyde.

The alveolar structure of the 48-h group was severely damaged (Fig. 1C), with a large number of inflammatory cells and red blood cells diffused in the field of vision. Lung tissue injury was still apparent in the 72-h group (Fig. 1D). However, alveolar structure showed none of the damage visible in the 48-h group, suggesting recovery from hypoxic stress at the 72-h time point.

Electron microscopy demonstrated that the thickness of the basement membrane of the capillary increased, compared with the control group (Fig. 1E) to different extents. The control group was also used as a marker to measure the pathological damage of each group of rats. In the lung tissue of the $24 \mathrm{~h}$ group, the thickness of the capillary basement membrane increased to varying degrees. Alveolar septum capillary thickness also increased, and microvilli shedding was observed (Fig. 1F). In the $48 \mathrm{~h}$ group, alveolar wall capillary endothelial cell edema became more apparent (Fig. 1G). In the $72 \mathrm{~h}$ group, basal membrane partial shedding and blood-air barrier obviously thinning are still evident (Fig. 1H).

Transcriptome sequencing results. RNA sequencing analysis of lung tissues from rats in each group identified 1,728 differentially expressed genes in the $24 \mathrm{~h}$, and 2,148 differentially expressed genes were found in the $48 \mathrm{~h}$ group, and there were 8,201 genes of $72 \mathrm{~h}$ group differentially expressed relative to the control group. The differentially expressed genes were obtained by KEGG (Fig. 2). The present study focused on the IL-17 signaling pathway. The main differentially expressed genes in this pathway were IL-17C, NF- $\kappa \mathrm{B}, \mathrm{IL}-1 \beta, \mathrm{IL}-6$, and TNF- $\alpha$.

Expression of $I L-1 \beta, I L-6, I L-17 C, N F-\kappa B$, and $T N F-\alpha$ in rats subjected to 24,48 or 72 h of hypoxic stress. The expression of IL-17C was significantly upregulated in the 24,48 and $72 \mathrm{~h}$ groups, compared with the control group. NF- $\kappa \mathrm{B}$ expression was a significantly upregulated after 48 and $72 \mathrm{~h}$ of hypoxia. The expression of IL-1 $\beta$, TNF- $\alpha$ and IL- 6 was also significantly upregulated at all time points (Fig. 3).

Levels of GSH-Px, SOD and MDA in rats under hypoxic stress in different groups. The activity of SOD and GSH-PX decreased significantly after 24,48 and $72 \mathrm{~h}$ of hypoxia $(\mathrm{P}<0.01)$, while the expression of MDA increased significantly after 48 and $72 \mathrm{~h}$ of hypoxic stress $(\mathrm{P}<0.01$; Table II).

\section{Discussion}

After rapid exposure to a hypoxic environment, a series of reactions as oxidative stress response occur to adapt to the hypoxic environment and even damage the lung tissue. The main manifestations include diffuse swelling and hyperemia of both lungs, considerable leakage of protein-rich liquid into the alveolar cavity, thickening of the alveolar cavity (31), increasing the activity of macrophages and infiltration of inflammatory cells (32). Luo et al (33) and Guo et al (34) demonstrated that lung tissue injury was most serious after exposure to a simulated altitude of 5,000 $\mathrm{m}$ and $48 \mathrm{~h}$ of hypoxia. Li et al (35) also suggested that lung tissue injury was the most serious after exposure to a simulated altitude of $6,000 \mathrm{~m}$ and hypoxic stress lasting $72 \mathrm{~h}$. In the present study, Sprague-Dawley rats were exposed to a simulated altitude of $6,000 \mathrm{~m}$ and hypoxia stress lasting 24, 48 or $72 \mathrm{~h}$. Morphological examination of the lung tissues in each group suggested that the alveolar structure of rats in hypoxic stress groups was damaged to varying degrees. Lung tissue was damaged most severely after hypoxic stress lasting $48 \mathrm{~h}$.

The production of ROS and the elimination of antioxidants create a stable dynamic balance. When the organism is subjected to hypoxic stress, oxygen-free radicals accumulate in cells and damage lipids, proteins and DNA, thus causing lung tissue damage (36-38). The present study suggested that the activities of SOD and GSH-Px decreased and the expression of MDA increased as hypoxic stress was prolonged; that is, oxidative damage occurred in lung tissue under hypoxic stress.

Oxidative damage can directly stimulate macrophages to release IL-1 $\beta$. As a pro-inflammatory factor, IL- $1 \beta$ can initiate immune response and recruit centralized granulocytes, macrophages and other inflammatory cells, which in turn can to infiltrate tissues and release IL-6 and TNF- $\alpha$ (39). The results of the present study demonstrated that IL-1 $\beta$ levels were highest after $24 \mathrm{~h}$ of hypoxic stress, while IL- 6 and TNF- $\alpha$ expression was highest after $48 \mathrm{~h}$ of hypoxic stress. GSH-Px and SOD activity were the lowest after $48 \mathrm{~h}$ of hypoxia stress, and MDA was highly expressed, suggesting that inflammation and the exudation of tissue fluid in lung tissue were further aggravated. The injury to alveolar epithelial cells and pulmonary interstitial edema was most pronounced at $48 \mathrm{~h}$. Previous studies demonstrated that IL-17C was not produced by activated T cells (22); rather, it is secreted by the epithelial cells of various tissues (40). In the present study, it was hypothesized that, given the aforementioned three factors, pulmonary epithelial cells could also participate in the immune response. The presence of large quantities of IL-17C activates the NF- $\kappa \mathrm{B}$ pathway and participates in the onset and development of AMS. According to the experimental results of the present study, IL-17C stimulation could increase the expression of $N F-\kappa B$ 
in the AMS rat model. The combined stimulation of IL-17C and NF- $\kappa \mathrm{B}$ also increased the expression of IL-17C, NF- $\kappa \mathrm{B}$, TNF- $\alpha$, IL-1 $\beta$, and IL-6 in alveolar epithelial cells, which also reflects the positive feedback regulation of IL-17C on the acute inflammatory response of pulmonary epithelial cells.

The innovation of the current study was the combination of hypoxia-induced oxidative stress and excessive inflammation to study the damage to the body. Under hypoxic stress, rats quickly initiate the oxidative stress response and immune response, but it is worth noting that, with the prolongation of hypoxic stress time, excessive oxidative stress can further stimulate the immune system, and release a large number of inflammatory factors, which accumulate in the body, and even lead to the occurrence of inflammatory storms.

According to the literature, IL-17C can also regulate the expression of IL-1 $\beta$, TNF- $\alpha$, and IL- 6 . However, the expression of these three factors was downregulated in the 72-h group. The specific molecular mechanism needs further study, and it may be related to the immune regulatory function of 1,25-dihydroxyvitamin D3 (41), studied earlier by our group.

\section{Acknowledgements}

Not applicable.

\section{Funding}

The present study was supported by The Second Tibetan Plateau Scientific Expedition and Research Program (grant no. 2019QZKK0606), The Chinese National Natural Science Foundation (grant no. 81460051), The Key Laboratory of Medicinal Animal and Plant resources of The Qinghai-Tibetan Plateau (grant no. 2017-ZJ-Y13), The Department of Science and Technology of Qinghai Province (grant no. 2019-ZJ-7042), The Scientific Research for Middle-aged and Young people of the Medical College of Qinghai University (grant no. 2018-kyy-1), and The National Students' Platform for Innovation and Entrepreneurship Training Program (grant no. 201910743003).

\section{Availability of data and materials}

The datasets used and/or analyzed during the current study are available from the corresponding author upon reasonable request.

\section{Authors' contributions}

XP contributed to the idea of the study and served an important role in interpreting the results. FL contributed significantly to analysis and manuscript preparation. XL performed data analysis and wrote the manuscript. ZC and RW helped perform the analysis with constructive discussion. All authors read and approved the final manuscript.

\section{Ethics approval and consent to participate}

The animals involved in the present study were handled in accordance with the National Regulations on the Administration of Laboratory Animals (GB14923-2010). The animal experiment scheme was approved and examined by the Ethics Committee of School of Medicine of Qinghai University.

\section{Patient consent for publication}

Not applicable.

\section{Competing interests}

The authors declare that they have no competing interests.

\section{References}

1. Tang E, Chen Y and Luo Y: Dexamethasone for the prevention of acute mountain sickness: Systematic review and meta-analysis. Int J Cardiol 173: 133-138, 2014.

2. Guo P, Luo H, Fan Y, Luo Y and Zhou Q: Establishment and evaluation of an experimental animal model of high altitude cerebral edema. Neurosci Lett 547: 82-86, 2013.

3. Swenson ER, Maggiorini M, Mongovin S, Gibbs JS, Greve I, Mairbäurl $\mathrm{H}$ and Bärtsch P: Pathogenesis of high-altitude pulmonary edema: Inflammation is not an etiologic factor. JAMA 287 : 2228-2235, 2002.

4. Zhao S, Zhang L, Lian G, Wang X, Zhang H, Yao X, Yang J and Wu C: Sildenafil attenuates LPS-induced pro-inflammatory responses through down-regulation of intracellular ROS-related $\mathrm{MAPK} / \mathrm{NF}-\kappa \mathrm{B}$ signaling pathways in $\mathrm{N} 9$ microglia. Int Immunopharmacol 11: 468-474, 2011.

5. Wyse C, Cathcart A, Sutherland R, Ward S, McMillan L, Gibson G, Padgett $M$ and Skeldon K: Effect of maximal dynamic exercise on exhaled ethane and carbon monoxide levels in human, equine, and canine athletes. Comp Biochem Physiol A Mol Integr Physiol 141: 239-246, 2005.

6. Balan DJ, Rajavel T, Das M, Sathya S, Jeyakumar M and Devi KP: Thymol induces mitochondrial pathway-mediated apoptosis via ROS generation, macromolecular damage and SOD diminution in A549 cells. Pharmacol Rep 73: 240-254, 2021.

7. Ma Y, Wang D, Xu X, Yang X, Wang X, Zhu Z, Zhao Y, Chen M, $\mathrm{Xu} F, \mathrm{Fu}$ L, et al: Dynamic changes of ROS, MDA and SOD during arsenic-induced neoplastic transformation in human keratinocytes. Wei Sheng Yan Jiu 44: 456-461, 2015 (In Chinese).

8. Zi Y, Jiang B, He C and Liu L: Lentinan inhibits oxidative stress and inflammatory cytokine production induced by benzo(a)pyrene in human keratinocytes. J Cosmet Dermatol 19: 502-507, 2020.

9. Altamura S, Bärtsch P, Dehnert C, Maggiorini M, Weiss G Theurl I, Muckenthaler MU and Mairbäurl H: Increased hepcidin levels in high-altitude pulmonary edema. J Appl Physiol (1985) 118: 292-298, 2015.

10. Gao H, Liu L, Zhao Y, Hara H, Chen P, Xu J, Tang J, Wei L, Li Z, Cooper DK, et al: Human IL-6, IL-17, IL-1 $\beta$, and TNF- $\alpha$ differently regulate the expression of pro-inflammatory related genes, tissue factor, and swine leukocyte antigen class I in porcine aortic endothelial cells. Xenotransplantation 24, 2017.

11. Sun $\mathrm{Y}, \mathrm{Hu} \mathrm{G}$, Zhang $\mathrm{X}$ and Minshall RD: Phosphorylation of caveolin-1 regulates oxidant-induced pulmonary vascular permeability via paracellularand transcellular pathways. Circ Res 105: 676-685, 2009.

12. Shukla D, Saxena S, Jayamurthy P, Sairam M, Singh M, Jain SK, Bansal A and Ilavazaghan G: Hypoxic preconditioning with cobalt attenuates hypobaric hypoxia-induced oxidative damage inratlungs. High Alt Med Biol 10: 57-69, 2009.

13. Gonzalez NC and Wood JG. Leukocyte endothelial interactions in environmental hypoxia. Adv Exp Med Biol 502: 39-60, 2001.

14. Xiao-Lin MA, Jin RB, Zhang XH, Cui GY, Ren XJ, Shi H and Sun YQ: Study on management of 726 victims in military hospitals following Yushu earthquake in Qinghai province. J Traumat Surg 4: 339-343, 2010 (In Chinese).

15. Tang C, Luo Y, Li S, Huang B, Xu S and Li L: Characteristics of inflammation process in monocrotaline-induced pulmonary arterial hypertension in rats. Biomed Pharmacother 133: 111081, 2021.

16. Han Z, Li X, Cui X, Yuan H and Wang H: The roles of immune system and autoimmunity in pulmonary arterial hypertension: A review. Pulm Pharmacol Ther 102094, Nov 2, 2021 (Epub ahead of print). 
17. Hu DL, Yu YX, Liang R, Zhou SY, Duan SL, Jiang ZY, Meng CY, Jiang W, Wang H, Sun YX and Fang LS: Regulation of hypoxia inducible factor- $1 \alpha$ on permeability of vascular endothelial cells and the mechanism. Zhonghua Shao Shang Za Zhi 35: 209-217, 2019 (In Chinese)

18. Zhou Q, Luo Y, Li H, Li S, Zhang X, Gao W, Zheng B, Yang D, Liu F and Yuqi G: Epidemiological study of mountain sickness complicated with multiple organ dysfunction syndrome on the Qinghai-Tibetan Plateau: report of 103 cases. Sci Res Essays 5, 2010.

19. Althubiti M, Rada M, Samuel J, Escorsa JM, Najeeb H, Lee KG, Lam KP, Jones GD, Barlev NA and Macip S: BTK modulates p53 activity to enhance apoptotic and senescent responses. Cancer Res 76: 5405-5414, 2016.

20. Barbarulo A, Grazioli P, Campese AF, Bellavia D, Di Mario G Pelullo M, Ciuffetta A, Colantoni S, Vacca A, Frati L, et al: Notch3 and canonical NF-kappaB signaling pathways cooperatively regulate Foxp3 transcription. J Immunol 186: 6199-6206, 2011

21. Li H, Chen J, Huang A, Stinson J, Heldens S, Foster J, Dowd P, Gurney AL and Wood WI: Cloning and characterization of IL-17B and IL-17C, two new members of the IL-17 cytokine family. Proc Natl Acad Sci USA 97: 773-778, 2000.

22. Song X, He X, Li X and Qian Y: The roles and functional mechanisms ofinterleukin-17 family cytokines in mucosal immunity. Cell Mol Immunol 13: 418-431, 2016

23. Song X, Zhu S, Shi P, Liu Y, Shi Y, Levin SD and Qian Y IL-17RE is the functional receptor for IL-17C and mediates mucosal immunity to infection with intestinal pathogens. NatImmunol 12: 1151-1158, 2011.

24. Akitsu A and Iwakura Y: Interleukin-17-producing $\gamma \delta \mathrm{T}(\gamma \delta 17)$ cells in inflammatory diseases. Immunology 155: 418-426, 2018

25. Yamaguchi Y, Fujio K, Shoda H, Okamoto A, Tsuno NH, Takahashi K and Yamamoto K: IL-17B and IL-17C are associated with TNF-alpha production and contribute to the exacerbation of inflammatory arthritis. J Immunol 179: 7128-7136, 2007.

26. Ruiz de Morales JMG, Puig L, Daudén E, Cañete JD, Pablos JL, Martín AO, Juanatey CG, Adán A, Montalbán X, Borruel N, et al Critical role of interleukin (IL)-17 in inflammatory and immune disorders: An updated review of the evidence focusing in controversies. Autoimmun Rev 19: 102429, 2020.

27. Yu S, Luo X, Yang B, Xiao L, Wu X, Li H and Wu C: Poly-functional $\mathrm{T}$ helper cells in human tonsillar mononuclear cells. Eur Cytokine Netw 30: 114-122, 2019.

28. De-DonckerL, Picquet F, Petit J and Falempin M: Characterization of spindle afferents in rat soleus muscle using ramp-and-hold and sinusoidal stretches. J Neurophysiol 89: 442-449, 2003

29. Kanehisa M and Goto S: KEGG: Kyoto encyclopedia of genes and genomes. Nucleic Acids Res 28: 27-30, 2000.
30. Livak KJ and Schmittgen TD: Analysis of relative gene expression data using real-time quantitative PCR and the 2(-Delta Delta C(T)) method. Methods 25: 402-408, 2001.

31. Ryan CF, Lowe AA and Fleetham JA: Nasal continuous positive airway pressure (CPAP) therapy for obstructive sleep apnea in Hallermann-Streiff syndrome. Clin Pediatr (Phila) 29: 122-124, 1990.

32. Maggiorini M, Mélot C, Pierre S, Pfeiffer F, Greve I, Sartori C, Lepori M, Hauser M, Scherrer U and Naeije R: High-altitude pulmonary edema is initially caused by an increase in capillary pressure. Circulation 103: 2078-2083, 2001.

33. Luo X, Guo W, Xu R, et al: Effect of high altitude and hypoxia in simulated environment on HPT axis and expression of VEGF and HIF-1 in lung tissues of rats. Acad J Chin PLA Med Sch 37: 864-868, 2016 (In Chinese)

34. Guo W: The dynamic observation of hypothalamic-pituitaryadrenala axis/hypothalamic-pituitary-thyroid axis stress and the effect of lung and brain tissue under simulated high altitude hypoxia. Gan Su University of Chinese Medicine, 2016 (In Chinese).

35. Li Y: The research of hypoxia related genes in high altitude pulmonary edema. Qing Hai University, 2017 (In Chinese).

36. Brandon M, Baldi P and Wallace DC: Mitochondrial mutations in cancer. Oncogene 25: 4647-4662, 2006.

37. Morrow JD: Quantification of isoprostanes as indices of oxidant stress and the risk of atherosclerosis in humans. Arterioscler Thromb Vasc Biol 25: 279-286, 2005.

38. Zhou L, Aon MA, Almas T, Cortassa S, Winslow RL and O'Rourke B: A reaction-diffusion model of ROS-induced ROS release in a mitochondrial network. PLoS Comput Biol 6: e1000657, 2010.

39. Xiong R, Jiang W, Li N, Liu B, He R, Wang B and Geng Q: PM2.5-induced lung injury is attenuated in macrophage-specific NLRP3 deficient mice. Ecotoxicol Environ Saf 221: 112433, 2021.

40. Ramirez-Carrozzi V, Sambandam A, Luis E, Lin Z, Jeet S, Lesch J, Hackney J, Kim J, Zhou M, Lai J, et al: IL-17C regulates the innate immune function of epithelial cells in an autocrine manner. Nat Immunol 12: 1159-1166, 2011.

41. Uberti F, Lattuada D, Morsanuto V, Nava U, Bolis G, Vacca G, Squarzanti DF, Cisari C and Molinari C. Vitamin D protects human endothelial cells from oxidative stress through the autophagic and survival pathways. J Clin Endocrinol Metab 99: 1367-1374, 2014

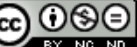

This work is licensed under a Creative Commons Attribution-NonCommercial-NoDerivatives 4.0 International (CC BY-NC-ND 4.0) License. 